\title{
Research on Qizi Mirror Excavated from the Tomb of King Munyong
}

\author{
Kaiwen $\mathrm{Zuo}^{1^{*}}$, Xuejuan Cheng ${ }^{2}$ \\ ${ }^{1}$ Department of Cultural Heritage and Museology, Nanjing Normal University, Nanjing 210097, China \\ ${ }^{2}$ Department of History, Anhui University, Hefei 230000, China \\ Email: kaiwenzuo@qq.com
}

\begin{abstract}
The tomb of King Munyong is a major archaeological discovery in South Korea in the 20th century, in which two mirrors with the seven breasted beasts mirror were unearthed. Japanese scholar Takayasu Higuchi thinks that these two bronze mirrors are all Qizi mirrors, while Chinese archaeologist Yang Hong thinks that only one can be called Qizi mirror. According to archaeological findings and literature, Yang Hong's view should be more reasonable. In addition, combined with the archaeological findings in China, it can be found that the Qizi mirror, as an accessory of tomb, may be related to the gender of the tomb owner.

Keywords: the tomb of King Munyong, Qizi mirror, Takayasu Higuchi, Yang Hong
\end{abstract}

\section{Introduction}

In 1971, the South Korean archaeological Department discovered the tomb of King Munyong in Songsanni, Kongju, Chungcheongnam-do. Songsanni, Kongju, as is known to all, several tombs apparently of the royal family of Paekche are located. During the Japanese occupation period, Japanese scholars excavated several tombs in Songsanni, like Songsanni Tomb No. 6.

The tomb was excavated in 1971. It is a north-south brick chamber tomb, from south to north by the tomb passage and tomb chamber. The tomb ramp is 9.3 meters long. The passage and the tomb all use brick to build voucher top. The passage is 2.9 meters long, 1.04 meters wide, 1.45 meters high. The tomb is 4.2 meters long, 2.72 meters wide and 2.93 meters high. There are two niches on the east and west walls, and one on the north wall. At the bottom of the tomb is a brick drainage ditch, and on the tomb is a circular mound with a diameter of about 20 meters. Tomb bricks have two kinds of rectangular and wedge; the latter is used specially from coupons, rick surface or plain surface, or printing money shape, diamond and lotus shape and other patterns. There are two wooden coffins on the coffin bed, the male coffin in the east, the female coffin in the west. The head of the corpse was north and south, and the body was straight. Inside the coffins are decorated with gold, silver, jade, and glass crowns and hairpins, as well as wooden pillows, bronze mirrors, and iron knives decorated with gold and silver. There are also celadon four-ear pot, six-ear pot and bronze pot, iron, spoon, chopsticks, mirrors and other products of the Southern Dynasty of China. Two sides of the tomb are built in the path, and a stone tomb animal is set behind the tomb. According to the epitaph, the owner of this tomb is King Munyong and his wife.

King Munyong was born in 461. He is the second son of Tongsong and great grandson of the aforementioned King Kaero. According to the Samguk Saki, in 501, he became the 25th king of Paekche. By his administration, Paekche became great again, and was recognized by the southern Chinese authorities. Liang gave the title of Ning Dong Jiangjun (Great General of Pacifying the East) to King Munyong. In May 523, he died. According to the stone epitaph discovered inside his tomb, the king's body was kept at a temporary funerary for 29 months until August of 525. King Munyong's princess died 14 months later in November 526 and she was also not buried until 29 months later.

In King Munyong and his wife's tomb, three bronze mirrors were unearthed, the two bronze mirrors are the seven breasted beasts mirrors. Another bronze mirror is a relief mirror. This paper will make a research on the seven breasted beasts mirror.

\section{The two bronze mirrors unearthed in the tomb of King Munyong}

According to the archaeological excavation report, The tomb of King Munyong, the two bronze mirrors, one unearthed in the coffin of the king and the other found in the coffin of the princess, are described as follows.

\subsection{The bronze mirror unearthed from the king's coffin}

The diameter of the mirror is $23.2 \mathrm{~cm}$, and the ornamentation is corroded. On the back of the bronze mirror, there are nine small breast nails around the round button, in which there are images and words, the words are " 宜子孙 " (It means 
that children and grandchildren can live a happy life). The outer side of the button seat is arranged with two pieces of plain loops, and the outer side is a wider main area. The main area is divided equally by seven breast nails placed on the four leaf pedestal. Between the breast nails are seven relief images, and the specific pattern is unknown. The outer region is flat, higher than the inner region, and seems to be decorated with flowers, plants, birds and animals.

\subsection{The bronze mirror unearthed in the coffin of the princess}

The diameter of the mirror is $18.1 \mathrm{~cm}$. On the back of the bronze mirror, there are nine small breast nails around the button. On the outer side of the button seat are two rings of bar toothed belt with a wide plain belt sandwiched between them. The main area is divided equally by seven breast nails, and between the breast nails are seven divine animal patterns outlined with thin lines. Because the lines of the image are thick and blunt, and covered with thin rust, the pattern is not clear. However, the images of green dragon, rose finch, unicorn, white tiger and toad can still be identified. There are two circles on the outside of the breast nail, with eight continuous arc lines between them. The outer part is a flat edge, on which there are patterns.

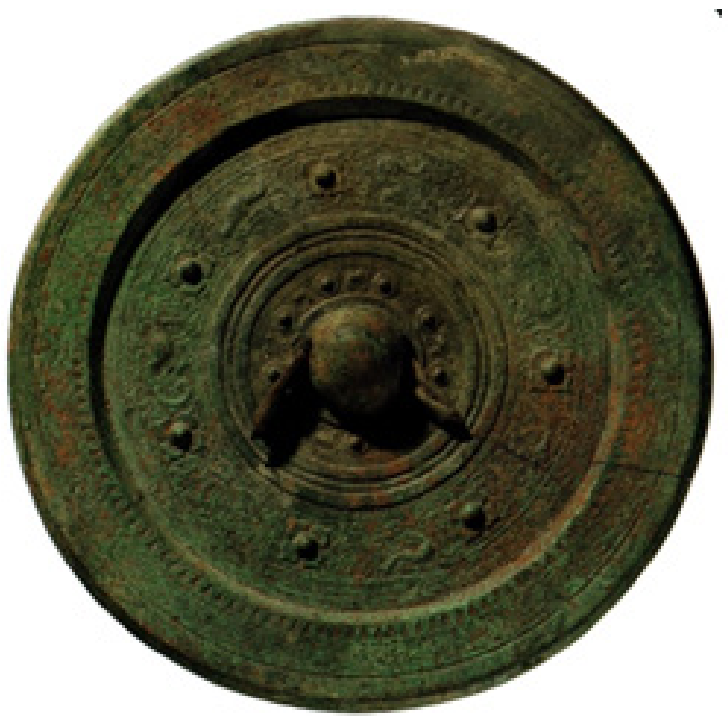

a

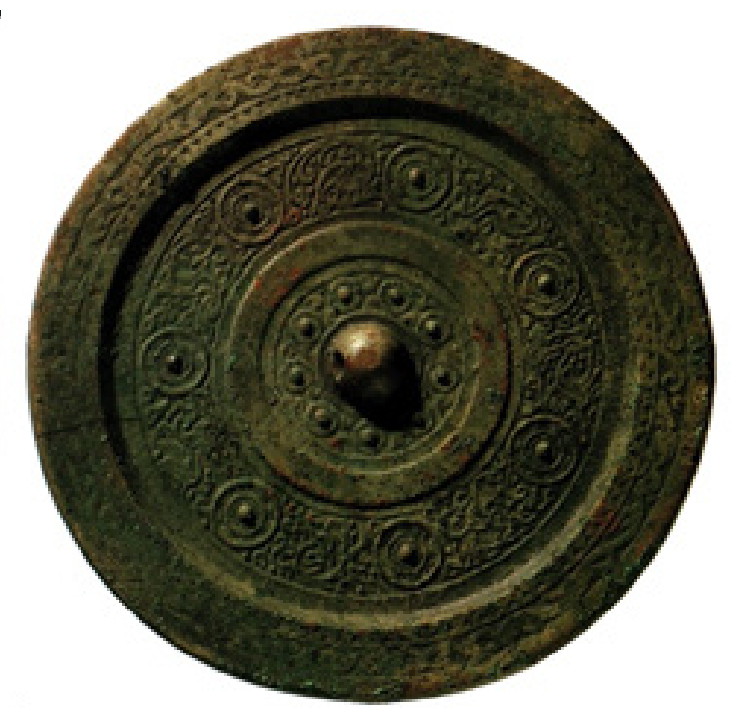

$\mathrm{b}$

Figure 1. Two seven breasted beasts mirrors excavated from the tomb of King Munyong

Note: a. Unearthed in the king's coffin; b. Unearthed in the coffin of the princess (Qizi mirror)

In 1972, Japanese scholar Takayasu Higuchi published the article The Mirrors Dug from the Tomb of King Munyong and the Nanatsuko-no-kagami in The SHIRIN, an academic journal sponsored by the Society for Historical Research of Kyoto University. He combined the relevant archaeological data from China and Japan and concluded that the seven breasted beasts mirror is the "Qizi mirror" contained in the literature of both countries, and that "Qizi" refers to the Qizi Mirror, thus pointing out that the two seven breasted beasts mirrors excavated from the tomb of King Munyong are both Qizi Mirrors (Takayasu Higuchi, 1972). In the 1980s, Yang Hong (2018: 176)offered a different perspective. He believed that Qizi Mirror was only a special type of mirror of the seven breasted beasts mirror, and that the seven breasted four gods and beasts mirror found in the coffin of princess was the Qizi Mirror, which Sun Ji and Wang Zhongshu later adopted in their treatises.

In addition to the above two views, there are also the "mirror platform theory" and the "bell mirror theory" in the scholarly community regarding the definition of Qizi mirror. The "mirror platform theory" is proposed by Chinese scholars. In the Dictionaries, 1979 revised edition of the dictionary source said Qizi mirror is "a mirror table with seven mirrors". The "bell mirror theory" was proposed by the Japanese scholar Kita Sadayoshi, and Ichisada Miyazaki (2018: 79) also said that "Qizi mirror is a seven-angle mirror with a decorative jade at the tip of each corner, which may be the original form of the imitation bell mirror that appeared later." From these two points of view, the bronze mirrors produced in the tomb of King Munyong are not Qizi mirror. However, the "mirror platform" has been refuted by Mr. Yang Hong. As for the "bell mirror theory", Japanese archaeologist Harada Yoshito (1933: 29) believes that the bell mirror is a unique mirror in Japan. And before the Tang Dynasty, all Chinese mirrors were round, so the "bell mirror theory" is basically not accepted by the academic community. The following is an analysis of two views of Takayasu Higuchi and Yang Hong. 


\section{Analysis of the two views of Takayasu Higuchi and Yang Hong}

The views of Takayasu Higuchi have had a great influence on the Chinese academic community, and many people have followed his words (Zhou Yuxing, 2005: 89; The Institute of Archaeology Chinese Academy of Social Sciences, 2018: 634). Some scholars have relied on inscriptions such as "Seven sons and nine grandsons each have their own happiness" on individual mirrors, suggesting that the "seven sons and nine grandsons" refer to the breast pegs in the inner area and in the button base, respectively. This can be regarded as a confirmation of Higuchi's saying that "Qizi" refers to the nipple. Some bronze mirrors have inscriptions such as "six sons of great fortune", "eight sons and nine grandsons", "eight sons and twelve grandsons", "seven sons and nine grandsons" and other inscriptions. Some scholars find that these bronze mirrors in the Eastern Han period are called "Liuzi mirror", "eight sons nine grandson mirror" (referred to as "Bazi mirror"), "eight sons and twelve grandsons mirror" (abbreviated as "Bazi mirror"), "seven sons and nine grandsons mirror" (abbreviated as "Qizi mirror"), and that "we have every reason to restore the original names of these mirrors based on their inscriptions and historical materials, and to rename the 'nipple pattern' on the Han mirror as the 'son and grandson pattern'" (Chen Xiaobo, 2004: 115).

In fact, a quick search of the relevant data reveals that the inscriptions of "a certain son and a certain grandson" in the mirror with multiple breast and animal motifs do not exactly match the number of breast pegs on the mirror. For example, the Chinese Bronze Mirror Catalogue recorded "Hou's seven breasted beast mirror". Although the inscription says "seven sons and eight grandsons live in the center", the actual outside of the mirror button has nine small breasted nails. Another example is "Zhang's five breast beast mirror" on the casting of "eight sons and nine grandsons living in high hall" inscription. The text and the number of nails also do not match. In addition, "a certain son of a certain grandson" type mirror inscriptions in other mirror style also appear. For example, "Cai's gods and goddesses on horseback" inscribed with "Seven sons and nine grandsons each have their own happiness", and the mirror has only four pegs. And the "Catalogue" recorded "good bronze four gods Bo bureau mirror", "Luoyang unearthed bronze mirror" Figure 29 "Xin Mang birds and animals rules mirror" and "Zhejiang unearthed bronze mirror" Figure 20 "East Han rules four gods mirror", are cast with "eight sons and nine grandsons rule the central" language. These three bronze mirrors have eight breast pegs in the main decoration area, but there are 12 small breast pegs outside the mirror button. It can be seen that "a certain son of a certain grandson" type of inscription, should be the mirror inscription format fixed auspicious words, and the number of nails is not directly related. It is questionable that all the mirrors with seven breasts and animals are regarded as "Qizi mirrors" based on such inscriptions. In addition, as is well known, the pegs on Han mirrors were often used to divide the ornamentation of the inner area, acting as a decorative embellishment. It is also undesirable to name the mirror as the socalled "Liuzi mirror" or "Bazi mirror" according to only a few words in the inscription, without distinguishing the specific situation and treating all the pegs as "zi pattern".

Compared with Takayasu Higuchi, Yang Hong has a clearer definition of the concept of "Qizi mirror". He believes that the "Qizi mirror" refers only to the seven breast and animal mirrors, the inner area of the pegs is even arc pattern, "Qizi" refers to the breast pegs and even arc pattern pegs seat composed of "even arc pattern mirror" shape pattern. By searching the relevant literature, I found that there was a kind of tableware called "Qizilei" or "Qizihe" in the Wei, Jin and North and South Dynasties. Yiwen Leiju volume 82 quotes Du Lanxiang Farewell and Taiping Yulan; volume 849 quotes Jin Dynasty ancestors' Ghost. They all tell a story that the fairy provides food for mortal men, and the vessel containing the food is called "Qizilei" or " Qizihe ". According to Mr. Yu Jiaxi, the so-called " Qizihe" is the present-day food box. Archaeologists have also found Qizilei objects several times in tombs from this period. For example, a lacquer Qizi box was excavated from the tomb of Zhu Ran in Ma'anshan, Anhui Province, which is rectangular in shape and divided into seven compartments. As can be seen from the objects, the "Qizi" in Qizilei refers to the seven internal compartments, each of which serves the same function as the entire Qizilei and is used to store dishes. Therefore, I speculate that those who are called "Zi" (son) should have some similarity in function or shape with the mother. The difference between the bronze mirror and the peg is large, while the figure composed with the peg and the peg holder is very similar.

Therefore, among the bronze mirrors excavated from the tomb of King Munyong, the mirror with seven breasts and four gods and animals placed in the coffin of the princess may be Qizi mirror. In summary, by analogy with the nomenclature of related cultural relics, it can be seen that Yang Hong has captured the main features of the Qizi Mirror, and the interpretation of the relationship between "mother" and "son" is more scientific and reasonable. In other words, Yang Hong's definition of the "Qizi Mirror" is more credible than that of Takayasu Higuchi. 


\section{Research literature about Qizi mirror}

It is no coincidence that Qizi Mirror was used as a burial object for the consort of King Munyong. On the one hand, the royal family of Baekje possessed the Qizi Mirror long before King Munyong. According to the Nihonshoki, in the 52nd year (252?) of the Jingu Koudou In the ninth month of the autumn, King Shogu of Baekje sent Kyuji and others to the Japanese kingdom and presented him with a Qizhi sword and a Qizi mirror. On the other hand, Qizi Mirror is the finest of mirrors from the North and South Dynasties. Xiao Liang Emperor Jian Wen "looking at the moon" said "the shape of the same Qizi mirror, shadow class nine autumn frost", the Northern Zhou poet Yu Xin with the same title poem praise said: "shining people are not Qizi, containing the wind is different from the Jiuhua". The two poets of the Northern and Southern Dynasties both compared the bright moon to the Qizi mirror, and Baekje presented the mirror to the Japanese as a national gift, which shows how exquisite and precious the mirror is. In addition, the identity of the users of the Seven Sons Mirror can be seen from these documents, which is confirmed by the mirror excavated from the tomb of King Munyong.

In addition to the above cited several records about Qizi mirror, the author recently found a document that may provide new clues to further understanding of Qizi mirror. In the Quan Shanggu, Qin, Han, San guo, Liuchao Wen, Volume 14, Zhaochen Guanbei, there is a sentence that reads, "The mirror of the four baht and Qizi was led to become a sword". Zhaochen Guanbei, also known as the Yushan Zhaochen Guanbei, was made by Emperor Xiao Gang of the Liang Dynasty. The text says that in 503, Zhang Daoling, the twelfth grandson of Zhang Daoyu, a Taoist priest of the Eastern Han Dynasty, went to Mount Yu in Haiyu County (Changshu, Jiangsu Province) and built the Zhaozhen Pavilion after more than ten years of seclusion. The article Zhaochen Guanbei depicts the Zhaozhen Pavilion and its surroundings, and records Zhang Daoyu's Taoist activities. According to related scholars, the Zhaozhen Pavilion Monument was probably made for the Zhaozhen Pavilion in the second year of the common era (521) after Xiao Gang became the assassin of South Xuzhou, and the monument had ceased to exist by the late Northern Song Dynasty.

According to the author's testimony, the so-called "four baht" should refer to a type of mirror with Sunlight even arc pattern and arc patterns that was popular from the Han Dynasty to the Wang Mang period. The phrase "Qizi mirror of the four baht, led into a sword" is meant to reflect the excellent bronze quality of Qizi mirror by fusing Qizi mirror with Sunlight even arc pattern.

From the documents, Qizi mirror is exquisite in style and material, and can be considered a rare and precious mirror at that time. However, based on the description in the archaeological report, it seems difficult to equate the seven breasted four gods and beasts mirror inside the coffin of the royal concubine of King Munyong with Qizi mirror in the literature of the North and South Dynasties because of its poor bronze quality and rough decoration. However, it is generally accepted in academic circles that the Eastern Jin and Southern Dynasties were the mid-decline period of Chinese bronze mirrors. The bronze mirrors from this period are not only fewer in number, but also shoddy and haphazardly made and poorly preserved. Therefore, compared with the bronze mirrors unearthed from ordinary tombs of the same period, Qizi mirror found in the tomb of King Munyong is a good product.

From the current archaeological discoveries in China, few "Qizi mirror" have been found in the tombs of the Eastern Jin and Southern Dynasties. On the one hand, this is certainly related to the fact that high-grade tombs of this period were mostly destroyed by robberies, and on the other hand, it also reflects the rarity of Qizi Mirror. Qizi mirror excavated from the tomb of King Munyong provides valuable physical information for the academic community to understand this mirror style. It is also noteworthy that a Qizi mirror was also found in the Sixth Dynasty tomb of Pensan Mountain (Pensan Tomb NO. 1) in Ma'anshan, Anhui Province. The diameter of the mirror is $16.2 \mathrm{~cm}$. The mirror button is semicircular, surrounded by 9 small breast nails, and the outside of the button seat is rolled grass strip and comb tooth ring strip in turn. The inner area of the bronze mirror is divided by seven breast nails, and the breast nails are decorated with green dragon, white tiger, rosefinch, Xuanwu and other patterns. Outside each breast nail is a breast nail seat composed of two circles, and there are symmetrical short string lines between the circles. The outer area is flat with serrated and rolled grass patterns. Excavators judged the tomb owner to be a woman. Combined with Qizi mirror in the coffin of King Munyong's princess, the author speculates that the seven sons mirror, as an accompanying burial object, may have some connection with the gender of the tomb owner. 


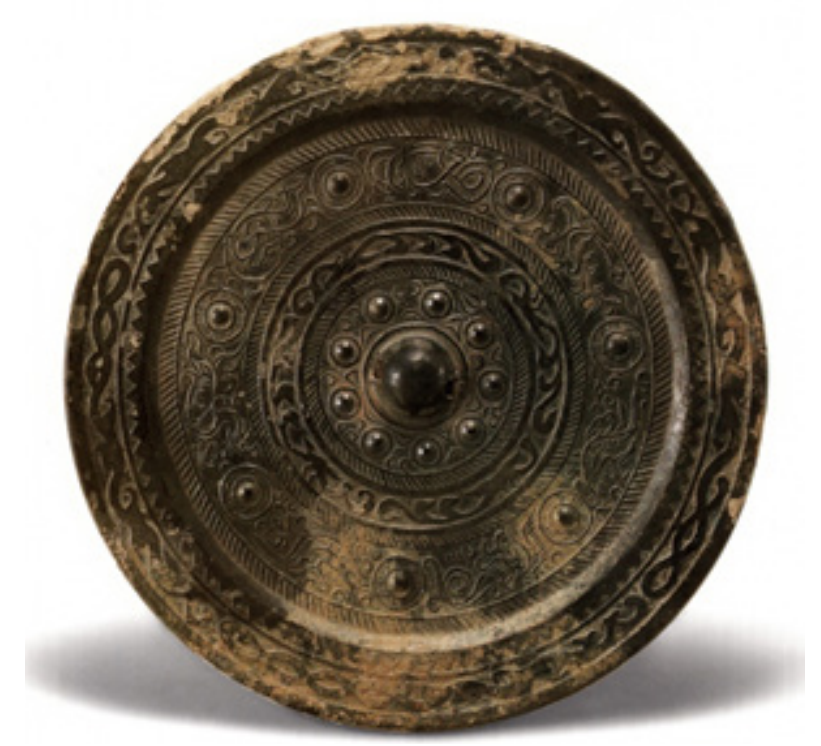

Figure 2. Qizi mirror unearthed from Pensan Tomb NO. 1

\section{References}

[1] Harada Yoshito. On the relationship between Chinese and Japanese ancient cultures from Archaeology; 1933.

[2] Yan Kejun. Quan Shanggu, Qin, Han, San guo, Liuchao Wen. Beijing: Zhong Hua Book Company; 1958.

[3] Ouyang Xun. Yiwen Leiju. Beijing: Zhong Hua Book Company; 1965.

[4] Takayasu Higuchi. The Mirrors Dug from the Tomb of King Munyong and the Nanatsuko-no-kagami. The SHIRIN. 1972; (4).

[5] Bureau of Cultural Property of ROK. The tomb of King Munyong. Tokyo: Student press; 1974.

[6] Wang Shilun. Bronze mirrors unearthed in Zhejiang. Beijing: Cultural Relics Publishing House; 1987.

[7] Luoyang Museum. Bronze mirrors unearthed in Luoyang. Beijing: Cultural Relics Publishing House; 1988.

[8] Kong Xiangxing. Chinese Bronze Mirror Catalogue. Beijing: Cultural Relics Publishing House; 1992.

[9] Chen Xiaobo. Research and analysis of "breast nail pattern" on bronze mirrors in Han Dynasty. In Collected works of Guangxi Museum. Nanning: Guangxi People's Publishing House; 2004.

[10] Zhou Yuxing. A study on the cultural relics unearthed from the mausoleum of the King Munyong (No.2): Take three bronze mirrors as an example. In Overseas investigation report of Paekche culture (No.5). National Museum of Gongju; 2005.

[11] Wang Jun. Excavation and Research on tombs of Six Dynasties in Ma'anshan. Science Press; 2008.

[12] Wang zhongshu. A Collection of Wang zhongshu's Works. Beijing: Social Science Literature Press; 2014.

[13] Sun Ji. Wake up from history: Sun Ji talks about Chinese Ancient Literature. Beijing: SDX Joint Publishing Company; 2016.

[14] Yang Hong. The sound of Antiquities: Daily life and culture of the ancients. Beijing: The Commercial Press; 2018.

[15] Ichisada Miyazaki. Enigmatic Qizhi sword: East Asia and Japan in the fifth century. Beijing: Citic Press; 2018.

[16] The Institute of Archaeology Chinese Academy of Social Sciences. Chinese Archaeology: The Three-Kingdoms to the Southern and Northern Dynasties Periods. Beijing: China Social Sciences Press; 2018. 